\title{
Output Characteristics of 'Chapparu' Brickwork
}

\section{Vasantha Abeysekera}

Abstract: Chapparu is an innovative practice borne out of adversity to cope with a wide variety of brick sizes to build walls of a given width. It is also the name given to mortar that is applied on the side of a brick on the header course to make the sides appear flat-as-a-plate when single-brick thick walls are built using the English bond. Moreover, it is also a type of joint which holds the bricks together. Such brickwork may be labelled as 'chapparu brickwork'.

Output characteristics of such brickwork are studied with respect to variations in brick and joint sizes using a simulation methodology. Simulation trials are undertaken using output rates of macroactivities established using the activity sampling and the synthesis techniques to establish rates and rates for 'three scenarios', viz. fastest and the slowest rates of working including an average rate. Brickwork output under different combinations of study variables are predicted by selecting a 'representative-unit' of brickwork in five randomly chosen walls for which purpose volume of mortar in different joints of the representative-unit and the number of bricks had to predicted using a separately validated model. Micro-activity rates were then used to build up the time taken for each course of brickwork and thereby predict the time taken for building a wall of a specific size. Hourly outputs were so calculated repeating the simulation for the 'three scenarios' as necessary. A general specification for increasing hourly output is developed using such analyses which recommends the use of large bed joints and taller bricks, in addition to smaller (or no) vertical joints adopting a flexible approach to lap requirements and joint sizes, including the use of under filled or unfilled vertical joints. Moreover, in order to minimise the negative impact of chapparu, it recommends smaller chapparu joints $(<10-12 \mathrm{~mm})$ as the impact on output is insignificant at such values when current methods of construction are used. Nevertheless, it is noted that increase in output may not necessarily translates to savings in cost.

The simulation methodology developed under this study is a versatile approach for evaluating different scenarios when compared with regression models. It can also be used for evaluating new methods of construction with relative ease.

It is expected that this first time study would clear common understandings surrounding chapparu brickwork thereby exploring new opportunities through a non-standardisation route!

Keywords: Activity sampling, brickwork joints, chapparu, productivity, simulation

\section{Introduction}

Despite centuries of use, there has been little understanding of an innovative practice known as 'Chapparu'. Indeed, this Sri Lankan practice borne out adversity to cope with many different sizes of bricks can be used to build a wall of a given width with many different sizes of bricks and joints. Moreover, it can be used to build a wide variety of wall widths as well with a given size of brick. Additionally, given that almost all brick walls in Sri Lanka are plastered on both sides, it opens up new opportunities to challenge the wisdom of practices used in developed nations which follow well established and entrenched norms of building with bricks. Interestingly, chaos in brick and joint sizes including wall widths presents new opportunities to investigate possible savings in time and costs when utilising non-standard approaches [1], [22].
Eng. (Dr.) Vasantha Abesekera, B.Sc. Eng. Civil (First Class Hons, Unio. of Moratuwa), M.Sc. (Construction Management, L'boro. Univ., UK), C. Eng., MIE(Sri Lanka), MNZIQS, Ph.D. (Construction Management, L'boro. Univ., UK), Director - Construction Management Studies, University of Southern Queensland, Australia; former recipient of $C, D, E$. Award. 


\section{Chapparu Brickwork}

'Chapparu' is a Sinhala word of Dutch origin [20], [21]. It is the name given to mortar that is applied on the side of a brick on the header course to make the side appear 'flat as a plate' when a single-brick thick wall is built using the English Bond (Fig. 1). This becomes a necessity when brick sizes are dimensionally uncoordinated, typically when bricks are produced by a cottage industry with the length of a brick either equal or shorter than twice its breadth $(\mathrm{L}=<2 \mathrm{~B})$. Walls built with such bricks and utilising 'chapparu' may thus be referred to as 'Chapparu Brickwork' and the resulting joint referred to as the 'Chapparu' joint.

Many have attempted to take the standardised route as a solution to this apparent problem with little success [2]. Anecdotally, there have been allegations that Chapparu walls take longer to build and cost more money. However, there are hardly any detailed studies pertaining to such brickwork let alone studies related to productivity of such walls. Hence, this study on output characteristics has much relevance.

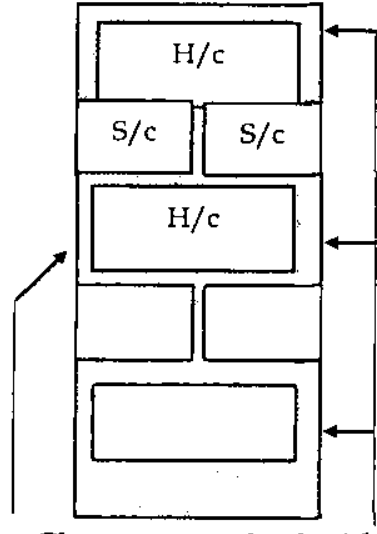

Chapparu on both sides

Type 1

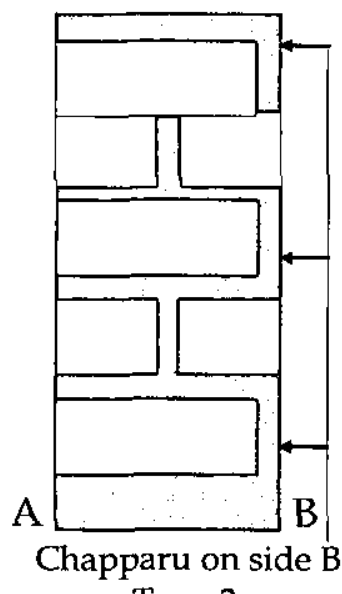

Type 2
The procedure used for building a 'Chapparu wall' (in brief) is to first fix the wall width (as required) by adjusting the bricks in the stretcher course $(\mathrm{s} / \mathrm{c})$ so that the header course bricks do not jut out when placed on top of the stretcher course. Once the bricks on the $s / c$ are laid (over a short stretch), the bricks on the header course $(\mathrm{h} / \mathrm{c})$ are laid on top (with or without plumbing and stringing as appropriate). Having then placed bed mortar on the $\mathrm{s} / \mathrm{c}$ and, thereafter, the $\mathrm{h} / \mathrm{c}$ bricks on top, mortar is applied on the side to fill the shortfall in the h/c bricks (see Fig. 1). Thus, it should be clear that it would be possible to build walls of varying widths by adjusting the size of the Chapparu with a corresponding adjustment of the wall joint (along the wall) in the s/c. Similarly, a wall of a given width may be constructed not necessarily out of few discrete sizes of bricks and a standard joint size, but with a variety of bricks and joint sizes. In other words, 'Chapparu' is an effective technology for coping with irregular brick sizes. In fact, there are three of types of 'Chapparu'. The walls so built appear 'flat as a plate' on both sides.

See Fig. 2 for a 3D view of a 'representative unit' including names of brickwork joints)

Fig. 1: Types of Chapparu Walls

\section{Study Aims and Methodology}

Given the above mentioned background, the main intention of this study is to understand the impact of brick and joint sizes (study variables) on 'output' of chapparu brickwork (CB) and thereby recommend strategies for optimising output. This is achieved by a simulation approach using macro-activity rates of brickwork (explained later) over the use of regression models. It should be noted that the word 'output' has been used in the context of 'output/bricklayer' (unless otherwise stated) over the more fancied word of 'productivity' for the sake of simplicity and also because 'productivity' connotes more deeper issues than 'output/bricklayer'.

Understanding factors that affect output (productivity) has been of much interest to researchers. For example, attempts have been made to forecast 'standard times' of brickwork 
activities by correlating factors which affect productivity [3], [4], [5] which are in essence regression-type models to predict productivity. Firstly, none of these (and other) studies have failed to examine the variation in joint sizes (such as bed joint and chapparu), height of the brick, under-filled joints and the like or for that matter to propose a methodology for such factors into account. Secondly, some of these studies have been on standard brickwork (with standard brick and joint sizes) which is not the case with chapparu brickwork as noted in Section 1. Thirdly, these models focuses on a 'single state of build' which is associated with a 'dubious' rating of 100 (as used in work-study techniques). Fourthly, output at a rating of 100 may not be sensitive to changes in study variables at other rates of working casting doubts on predictions made. Fifthly, forecasts could only be extended to situations covered by the data. Finally, a large volume of data would be required to cover a large set of variables incurring time and costs. These shortcomings and disadvantages cast doubts on the value of regression models for the task at hand. Nevertheless, such models were not fully discarded without further study.

The first, involved the collection of time data related to output which was analysed using broad indicators to isolate broad trends in relation to study variables (see Table 1) and correlate these indicators with study variables. For example, bricks/mason-hr. showed a positive association with mortar/mason-hour as would be expected. When the latter was deflated by the study variables such as wall thickness, bed mortar thickness, height of brick, etc., the observed variability diminished [6]. Further analysis with $\log$ functions correlated well when regressed. The equations developed were validated by use of site data. However, after much deliberation (see reasons given earlier), it was decided to discard its use as correlations as predicted by such models may also amount to a physical relationship between (say) the number of bricks and the volume of mortar. Moreover, the usefulness of such regression models built with historical data were found to be inadequate and doubtful for predicting and/or analysing outcomes related to future scenarios. Thus, this 'black box' approach to 'input' and 'output' lacked transparency and flexibility to account for methodological changes in bricklaying (say from a Type 1 to Type 2 walls). Hence, the 'model approach' was not favoured for investigating the impact of the study variables. As such, a new approach had to be conceived. The second approach which uses a simulation method using a 'representative unit' of brickwork as the basis for arriving at output (see Fig. 2) was found to be very useful for assessing the impact of study variables (explained later). It uses the technique of 'activity sampling' [7] for establishing times for various (micro) activities of brickwork (a total of 48 in all), and then using 'synthesis' [8] for setting up times for a group of (macro) activities (a total of 11 activities listed in Table 1) in order to compute 'macro-activity indicators' such as 'time for placing a brick', 'time for fetching a cubic meter of mortar' and 'time for filling a cu.m. of mortar into vertical-joints' (listed in Table 2). Although the above mentioned techniques were useful for establishing time data, there was a need to develop a methodology to establish mortar volumes as well so as to arrive at accurate indicators based on mortar volumes such as 'time for filling a cu.m. of mortar into vertical joints'.

Assessing the volume of mortar in brickwork joints was not a simple task. For example, field studies showed that simply subtracting the volume of bricks from the volume of the wall built did not equate to the volume of mortar used. A number of factors, such as 'fullness' of joints (F1-F5 as noted in Fig. 2), types of sand (fine, nedium, coarse), mortar mixes, number of brick bats used (i.e. broken bricks), accurate measures of brick and joint sizes, etc., had to be taken into account for building an accurate model to predict the volume of mortar in brickwork, hereinafter referred to as the RUM model [8]. These volumes were necessary for simulating the times taken to lay/fill mortar using macro-activity data as noted earlier. The actual procedure was simulating brickwork output using macro-activity data and the volumes of mortar in various joints under different conditions (such as when using different brick and joint sizes) and also under multiple scenarios such as the 'best case' (when activities are carried out at the fastest possible rate), 'most likely case' and 'worse case' (when activities are carried out at the slowest recorded rate) is described in sections 4.2 and 5 in detail. In order to facilitate the analysis of such data, it would be useful firstly to glean the impact of study variables (such as bed joint size) on output by reflecting on the time spent on various macro-activities in order to make some broad assertions on activity rates and brickwork output. 


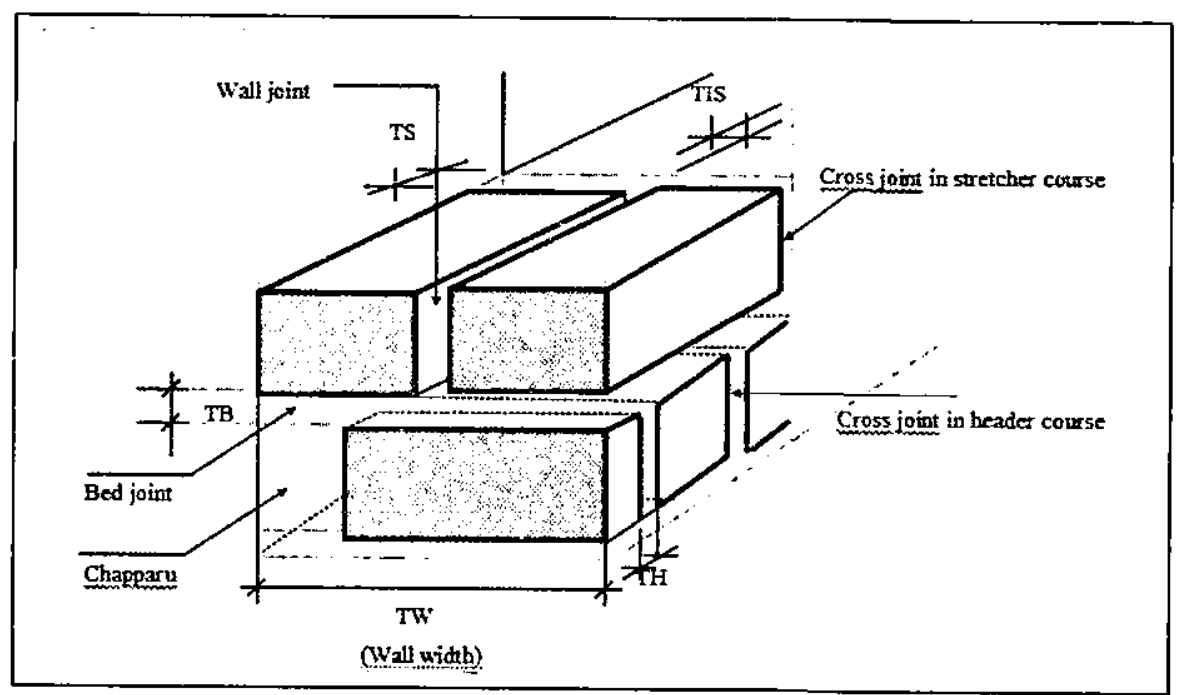

Fig. 2:

A 'representative unit' of bricks and joints for a Type 2 chapparu wall in English Bond (Note: For a type 1 wall, chapparu will be on both sides of the $h / c$; fullness factors of joints:

F1-bed joint, F2- chapparu, F3-h/c cross joint, F4- stretcher course cross joint, F5-wall joint; TB -thickness of bed joint sometimes referred to as bed mortar thickness or BMT)

\section{Broad Assertions using Macro} Activities

\subsection{Assertions based on Time Spent on Macro Activities}

As noted above, it would be useful to make some broad assertions on how output may be impacted upon by examining the time spent on macro activity data presented in Table 1. These data relate to five randomly chosen field walls that show significant deviations in study variables such as hourly output, wall width, brick and joint size (see Appendix 2). It is observed that:

i. Of the activities associated with the use of bricks, the largest portion of time was spent on 'placing bricks';

ii. Of the activities associated with the use of mortar, the largest portion of time was spent on 'fetching mortar' and 'filling vertical joints';

iii. The time spent 'spreading bed mortar' was small $(<10 \%)$; and

iv. The time spent on 'chapparu' was small $(<10 \%)$

An observation of considerable interest is the large proportion of time spent on filling vertical-joints and fetching mortar. However, if the time spent on 'fetch mortar' activity is apportioned to the respective joints (based on the volume of mortar in the different joints), it can be shown that this difference is marginal. Nevertheless, in view of the observations made by the author in a previous study that mortar in vertical joints is often less than one third of the total volume of mortar, the disproportionately large time spent on filling mortar leads to the following broad assertions [9]:

Assertion 1: The rate at which mortar is filled into vertical joints must be low;

Assertion 2: The rate at which mortar is spread on the bed joint must be high.

The first assertion, suggests that, higher outputs are more likely with larger bed joints (as a trade-off between the proportion of time spent on spreading bed mortar and the time spent on filling mortar in vertical joints). On the other hand, using larger bed joints mean replacing space allocated for bricks. Therefore, if bricks could be used to fill spaces faster, then the effect of using a larger bed joint to achieve higher levels of hourly outputs would be nullified. This is investigated further in the ensuing sections by obtaining simulated outputs due to changes in the size of the bed joints. 
Table 1:

Proportion of time spent on macro-activities of brickwork

\begin{tabular}{|c|c|c|c|c|c|}
\hline Case: & 1. & 2 & 3 & 4 & 5 \\
\hline \multicolumn{6}{|c|}{ Details of broad indictors of ficld walls } \\
\hline Bricks+ brick bats/m.hr & 85.23 & 102.06 & 109.06 & 120.55 & 180.30 \\
\hline Bricks (equated) $/ \mathrm{m} . \mathrm{hr}$ & 61.79 & 85.52 & 102.00 & 113.51 & 170.3 \\
\hline Sq.m./m.hr & $0.4 \overline{74}$ & 0.5974 & 0.737 & 0.7976 & 1.273 \\
\hline Cu.m./m.hr. & 0.0985 & 0.1195 & 0.154 & 0.1635 & 0.23 \\
\hline \multicolumn{6}{|c|}{ Time spent on macro-activities as a percentage of total time $(\%)$} \\
\hline 1. Set line & 7.4 & 4.8 & 13.6 & 9.0 & 4.8 \\
\hline 2. Plumb brick & 4.5 & 3.9 & 7.1 & 11.7 & 0.0 \\
\hline 3. Fetch brick & 7.8 & 6.9 & 7.7 & 9.9 & 4.8 \\
\hline 4. Place brick & 16.3 & 17.2 & 15.4 & 13.2 & 20.3 \\
\hline 5. Travel to fetch brick & 4.2 & 5.9 & 6.4 & 2.0 & 1.9 \\
\hline 6. Fetch mortar & 12.6 & 10.2 & 4.7 & 10.8 & 9.5 \\
\hline 7. Spread bed mortar & 4.9 & 5.9 & 9.5 & 9.0 & 5.7 \\
\hline 8. Fill vertical joints & 12.6 & 13.3 & 15.4 & 16.9 & 28.6 \\
\hline 9. Chapparu & 9.1 & 5.1 & 4.1 & 5.2 & 0 \\
\hline 10. Other & 12.2 & 10 & 13.1 & 6.6 & 15.8 \\
\hline 11. Idle/recover/relax & 8.4 & 16.8 & 3.0 & 5.7 & 8.6 \\
\hline Total & 100 & 100 & 1.00 & 100 & 100 \\
\hline
\end{tabular}

Notes: ' $\mathrm{m}$ ' refers to mason/bricklayer; 'bats' refer to broken bricks (such as half bricks); Time spent on spreading bed mortar includes filling wall joint as mortar simply falls into it when spreading bed mortar. (See Appendix 1 for an illustration of different types of joints)

Furthermore, arising out of the assertion that the rate filling mortar into vertical joints is low, it appears that the use of unfilled/under-filled vertical joints, or alternatively, the use of smaller vertical joints, would facilitate higher hourly outputs. It is interesting and useful to point out here that unfilled vertical joints do not have an impact on strength although may not be acceptable for other reasons such as sound insulation or rain penetration [10]. However, given that Sri Lankan brick walls are rarely if ever left unplastered, such issues would be of no relevance for this study. Thus, using under-filled/unfilled vertical joints seem to offer opportunities for increasing output.

On the issue of using taller bricks for higher output, it should be pointed out that if the height of the brick is increased, the trade-off between the time for placing a brick (per unit area or unit volume of wall) against the increase in the time for filling mortar into comparatively larger vertical joints needs to be considered. Thus, the effect of achieving higher outputs by using a taller brick may be negated by the increase in the time taken for filling vertical joints.

Thus, the above discussions lead to the following interim conclusions on brickwork output, which are investigated further in the ensuing sections:

i. Smaller vertical joints favour larger hourly output rates in view of the slow rate of placing mortar into vertical joints;

ii. The effect of using under-filled or unfilled joints would be similar; and

iii. The effect of using larger bed joints/taller bricks would be decided on the trade-off between the time for spreading/filling mortar and the time for laying bricks. 


\subsection{Exploring Assertions using Macro- Activity Output Rates}

In order to arrive at output rates (as against proportion of time for various activities), it was necessary to categorise these activities in to four main areas as listed below:

i. Activities which are associated with the bricks $(3,4$ and 5$)$

ii. Activities which are associated with volume of mortar $(6,7,8$ and 9$)$

iii. Activities which are associated with a course of brickwork ( 1 and 2)

iv. Activities which are not directly associated with any of the above (10 and 11)

For activities related to bricks (i.e. activities 3, 4 and 5 in Table 1), output rates were calculated by dividing the time taken by the number of bricks placed. However, it would be incorrect to resort to such a method for activities which are related with the use of mortar. Hence, the procedure adopted was to calculate the volume of mortar in joints using the RUM model described earlier taking into account of joint fullness factors, sizes of joints and the type of sand used as noted before. The volumes so obtained for the 'representativeunit' joints (viz., the bed mortar and wall joint, chapparu, and mortar in other vertical joints) were used to arrive at the total volumes in these joints by multiplying the 'representative unit' joint volumes by the ratio of 'area of wall built at site to the area of the representative unit'. The time taken to fill these joints were computed by multiplying the time taken to build the wall (such as field wall 1 - see Appendix 3) by the activity sampling indicators given in Table 1. Having so computed the volume of mortar in joints, it was an easy task to compute the time taken to use a cu.m. of mortar. As for the data on 'plumbing and setting line', the time taken was divided by the number of courses of brickwork (using data in Appendix 3).

There was some difficulty in arriving at a suitable basis for a rate indicator with respect to categories $10 \& 11$ in Table 1. Amongst the options open were to deflate the times so obtained by either the number of bricks, number of courses or by the volume of mortar.
Other options were to consider it as a factor based on the ratio of indirect time to direct time, or by the area of wall built, etc. Eventually, it was argued that category 10 (i.e. 'Other') be deflated by the number of bricks (or even by volume, if necessary) and category 11 (i.e. 'Relaxation ...') be considered as a factor based on the ratio of the time taken to that of the total direct time (i.e. activities 1 to 9 in Table 1). The values so obtained are given in Table 2.

The set of data in columns labelled as, 'slowest', 'average' and 'fastest' needs some explanation. These, in fact, form the three scenarios this study focuses on. The values given under the 'fastest' column refer to a situation where macro-activities are executed at the fastest recorded rate (i.e. using the minimum set of values in columns 1 to 5 in Table 8.3). Similarly, the values under 'slowest' case scenario refer to a situation where macroactivities are executed at the slowest rates (i.e. using the largest values in Table 8.3). The average values so obtained are the average of the 'slowest' and the 'fastest' values. However, the approach adopted with respect to category 11 (i.e. 'relaxation') was different when assigning values to these three scenarios. It was argued that, if bricklayers were to work at faster rates, then requirement for 'relaxation etc.' would be greater. As such, for the 'fastest' case scenario, the largest recorded value was posted. A point worth noting here is that this study could be repeated with a greater variety of walls but is considered adequate for the purpose at hand given the wide range of situations displayed by field walls as noted earlier (see also [9]).

Information in Table 2 confirms the initial assertions given in Section 4.1. For example, the rate of filling mortar into bed joint is much faster than filling mortar into vertical joint varying from (a ratio of) 5.69 to 20.39 . Furthermore, it is seen that the rate of using mortar for the chapparu joint is as low as filling mortar into other vertical joints. Thus, excessive use of chapparu should reduce output but what is not clear is to what extent it impacts. The simulation procedure mentioned in the following Section was used to assess these and other impacts. 
Table 2:

Indicators of rates of output of macro-activities

\begin{tabular}{|l|c|c|c|c|c|c|c|c|}
\hline \multicolumn{1}{|c|}{ Case (field walls): } & 1 & 2 & 3 & 4 & 5 & Slowest & Average & Fastest \\
\hline 1 Set line/course (s/pair) & 74.49 & 42.98 & 53.35 & 31.55 & 22.60 & 74.49 & 44.99 & 22.60 \\
\hline 2. Plumb/course (s/pair) & 45.30 & 34.92 & 27.85 & 41.01 & 0.00 & 45.30 & 29.82 & 27.85 \\
\hline 3. Fetch brick (s/brick) & 4.54 & 2.90 & 2.72 & 3.14 & 1.01 & 4.54 & 2.86 & 1.01 \\
\hline 4. Place brick (s/brick) & 9.50 & 7.24 & 5.44 & 4.19 & 4.29 & 9.50 & 6.13 & 4.19 \\
\hline $\begin{array}{l}\text { 5. Travel to fetch } \\
\text { bk.(s/bk) }\end{array}$ & 2.45 & 2.48 & 2.26 & 0.63 & 0.40 & 2.48 & 1.65 & 0.40 \\
\hline 6. Fetch mortar (s/cu.m.) & 11,691 & 6,203 & 3,090 & 8732 & 4275 & 11,691 & 6,798 & 3,090 \\
\hline 7. Bed mortar (s/cu.m.) & 5,442 & 4,160 & 8,408 & 10,244 & 3,299 & 10,244 & 6,311 & 3,299 \\
\hline 8. Vertical joint(s/cu.m.) & 111,009 & 86,919 & 47,534 & 58,804 & 57,928 & 110,009 & 72,239 & 47,534 \\
\hline 9. Chapparu (s/cu.m.) & 144,707 & 69,808 & 61,117 & 73,396 & - & 144,707 & 69,806 & 61,118 \\
\hline 10. Other (s/brick) & 7.11 & 4.21 & 4.62 & 2.09 & 3.34 & 7.11 & 4.27 & 2.09 \\
\hline 11. Idle/relax factor - \% & 9.17 & 20.17 & 3.09 & 6.04 & 9.41 & 3.09 & 9.58 & 20.19 \\
\hline
\end{tabular}

Note: Values given herein are per bricklayer (i.e. mason); $\mathrm{s}$ - seconds.

\section{The Simulation Procedure for Assessing Impacts}

As mentioned above, in order to study the impact of study variables the procedure set out below was adopted using the 'representative unit' (Fig. 2) as the basis for exploration.

Step 1: Suitable values for the wall length, its width, the brick size, type of sand, joint fullness factors were established first as demanded by the circumstance.

Step 2: The RUM method was used to compute the number of bricks and also the volume of mortar in the respective joints of a 'representative unit'. Thereafter, the volumes in different types of joints were aggregated to arrive at the total volume.

Step 3: The number of 'representative units' spanning the length of the wall was calculated by dividing the wall length by the length of the 'representative unit' (i.e. L+ TS).

Step 4: In order to arrive at values related to a course of 'representative units' (i.e. a stretcher course and a header course in English bond spanning the wall length) the data related to the 'representative unit' (computed in Step 2), was multiplied by the factor obtained in Step 3, to convert to course values.

Step 5: The time taken to build a course by a pair of bricklayers was calculated by multiplying the data so obtained by the 'macro-activity' rate indicators and dividing it by two. Thereafter, the time taken for plumbing and setting line was added to arrive at a total time for building a $\mathrm{h} / \mathrm{c}$ and a s/c (i.e. doubling the time for walls without chapparu and using only once for walls with chapparu say in the case of a Type 1chapparu wall).

Step 6: In order to arrive at the total time for a course (i.e. by a pair of bricklayers), the time computed in Step 5 above, was multiplied by the relaxation factor given in Table 2 .

Step 7: The area of wall built within this period of time, was calculated by multiplying the length of the wall by the height of the 'representative unit' (i.e. $2^{\star} \mathrm{H}+2^{\star} \mathrm{BMT}$ ).

Step 8: In order to compute the area of wall built within (say) one hour by a pair of bricklayer, the area obtained in Step 7 was divided by the time obtained in Step 6. To arrive at the corresponding value per mason hour, these values were halved. The volume of wall built, was then computed by multiplying the area so obtained by the wall width. The values related to bricks/m.hr were computed similarly.

The above procedure can now be used to compute 'output' under different conditions as dictated by different values of study variables under the three scenarios of 'fast', 'average', and 'slow' activity rates (see Table 2). The results obtained using this procedure is described in the following Sections.

\section{The Impact of Variations in Bed Joint}

As a preliminary investigation, it was decided to simulate changes in output when doubling the bed joint in relation to the five cases (used earlier) along with the rates of working specific to the case. The results are shown in Table 3. 
Table 3:

Percent increase in hourly outputs when doubling bed mortar joints

\begin{tabular}{|l|c|c|c|c|c|}
\hline \multicolumn{1}{|c|}{ Case 1: } & 1 & 2 & 3 & 4 & 5 \\
\hline Existing BMT (mm) & 21.07 & 23.41 & 13.67 & 10 & 15.15 \\
\hline Changed BMT (mm) & 10.54 & 11.70 & 27.34 & 20 & 30.30 \\
\hline & & & & & \\
\hline Sq.m.or Cu.m./M.hr. & 6.86 & 10.59 & 7.40 & $(0.27)$ & 7.06 \\
\hline
\end{tabular}

Note: Negative values are shown within parenthesis.

It can be seen from this Table that in all but one case (i.e. Case 4) there is a general increase in the hourly outputs when the bed joint size is doubled. Examination of macro-activity values in Table 2 show that the reason for Case 4 to show a decline was because it had the lowest rate of spreading bed mortar. However, in order to assess the output potential of these walls, different activity rates were used to establish the percentage increase in output with nine different combinations (simulating uncertainty) which are possible realities due to factors such as motivation of worker, workplace layout, and the like. The results are shown in Table 4.

What is interesting to note from the results in Table 4 is that of all the nine combinations, it is only in the third combination that there was a decline in the hourly output and that too, marginally. Thus, it may be concluded that in the case of the study walls, an increase in bed mortar would be unlikely to result in a reduction in hourly outputs. On the contrary, doubling the bed joint would be more likely to result in an increase in the hourly output. But, would this be the case with other types of wall widths too?

Table 4:

Sensitivity of hourly outputs to changes in macro-activity rates when doubling Bed-joint size (Increase in output as a \%)

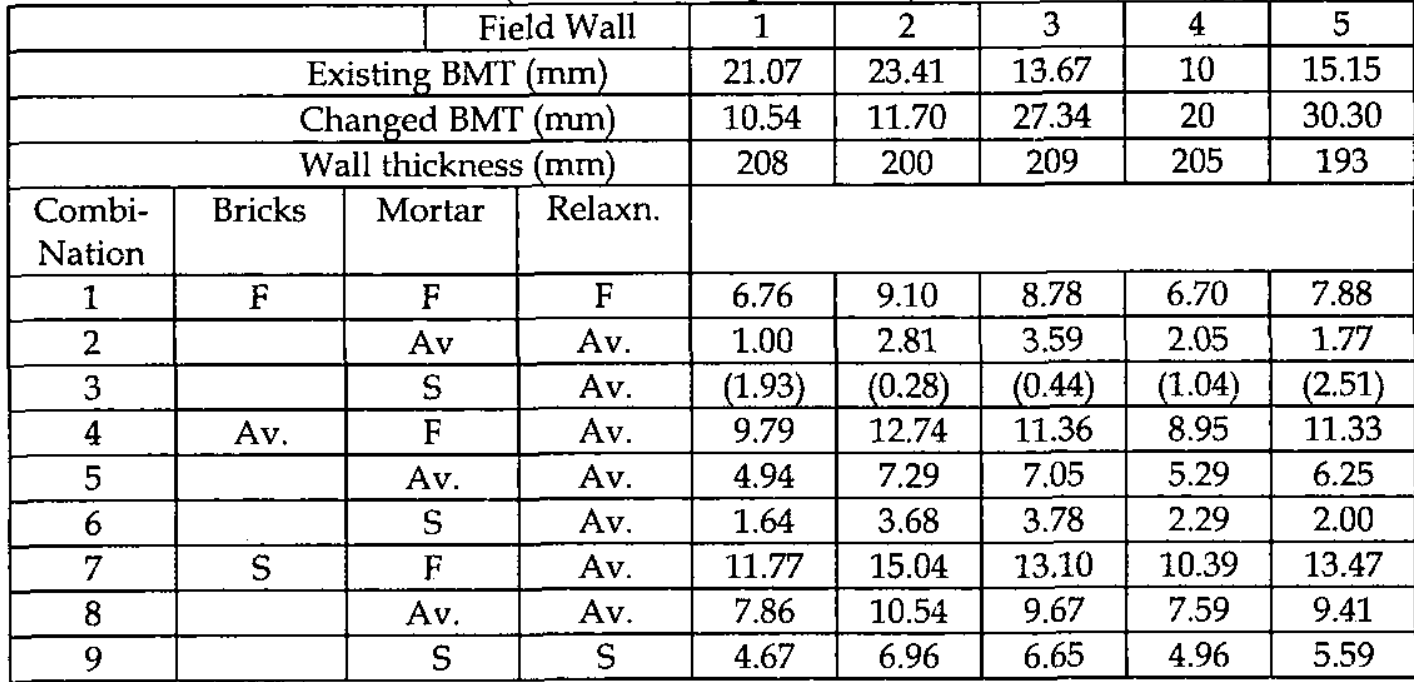

Note: Negative values are shown within parenthesis.
For this purpose, four walls with different widths of $190,200,215$, and $225 \mathrm{~mm}$ were selected (referred to as 'prescribed widths' see [2]). Firstly, it was decided to standardise the wall length to $3.5 \mathrm{~m}$ (as most walls in Sri Lanka are generally around 3 to $4 \mathrm{~m}$ ). Secondly, it was necessary to eliminate the influence of chapparu (by selecting bricks where its length was the width of the wall) corresponding roughly with the brick manufacturers' preferred format of $L \approx 2 B$ [11]. Thirdly, the height of the brick was standardised at $45 \mathrm{~mm}$ in view of the abundance of smaller size bricks. Fourthly, the size of the stretcher/header course cross joints were taken as $15 \mathrm{~mm}$ each (a size, tallying closely current practice) and the 'joint fullness factor' was set to 1.0. Finally, the number of combinations to be studied (for different bed joint sizes) was narrowed down to combinations 1, 3, 5, 7 and 9 listed in Table 4 . Thereafter, outputs were simulated with three different bed joints of 10 , 20 and $30 \mathrm{~mm}$. The results of this analysis are given in Table 5. 
Table 5:

Changes in of hourly outputs $(\%)$ when increasing bed mortar joints

\begin{tabular}{|c|c|c|c|c|c|c|c|}
\hline \multirow{2}{*}{\multicolumn{8}{|c|}{$\begin{array}{l}\text { DATA: Length of wall: } 3.5 \mathrm{~m} \text {. Walls without chapparu. } \\
\text { Medium type sand; } \mathrm{TS}=\mathrm{TH}=15 \mathrm{~mm} ; \mathrm{F} 1=1.1577 ; \mathrm{F} 2-\mathrm{F} 5=1.0 \\
\text { Brick sizes selected eliminates the use of chapparu }(\mathrm{mm}) \text { : }\end{array}$}} \\
\hline \multicolumn{3}{|c|}{$\begin{array}{l}\text { Brick sizes selected eliminates the use of chapparu (mm): } \\
\qquad \text { Case 1: TW }=190 ; 190 \times 92.5 \times 45 \quad \text { Case } 3: \text { TW }=215 ; 215 \times 105 \times 45\end{array}$} & & & & & \\
\hline \multicolumn{4}{|c|}{ Case $2:$ TW $=200 ; 200 \times 97.5 \times 45$} & \multicolumn{4}{|c|}{$\begin{array}{l}\text { Case 3: TW }=215 ; 215 \times 105 \times 45 \\
\text { Case 4: TW }=225 ; 225 \times 110 \times 45\end{array}$} \\
\hline \multicolumn{8}{|c|}{ A1-A5: Impact of BMT from 10 to $20 \mathrm{~mm}$} \\
\hline \multicolumn{4}{|c|}{ Case: } & 1 & 2 & 3 & 4 \\
\hline \multicolumn{4}{|c|}{ Wall thickness (mm) } & 190 & 200 & 215 & 225 \\
\hline & Bricks & Mortar & Relaxn. & & & & \\
\hline A1 & $\mathrm{F}$ & $\mathbf{F}$ & $\mathrm{F}$ & 8.25 & 8.41 & 7.56 & 7.00 \\
\hline $\mathrm{A} 2$ & & $S$ & Av. & 0.28 & $(0.54)$ & $(1.71)$ & $(2.46)$ \\
\hline $\mathrm{A} 3$ & Av. & Av. & Av. & 7.06 & 6.93 & 5.93 & 5.28 \\
\hline $\mathrm{A} 4$ & $S$ & $\mathrm{~F}$ & Av. & 12.09 & 13.41 & 12.88 & 12.53 \\
\hline A5 & & $S$ & $S$ & 6.59 & 6.36 & 5.33 & 4.66 \\
\hline \multicolumn{8}{|c|}{ B1-B5: Impact of BMT from 10 to $30 \mathrm{~mm}$} \\
\hline B1 & $\mathrm{F}$ & $\mathrm{F}$ & $\mathrm{F}$ & 14.29 & 15.54 & 13.87 & 12.78 \\
\hline B2 & & $\underline{S}$ & Av. & 0.48 & $(0.93)$ & $(2.93)$ & $(4.19)$ \\
\hline B3 & Av. & Av. & Av. & 12.23 & 12.65 & 10.75 & 9.53 \\
\hline $\mathrm{B} 4$ & $\underline{S}$ & F & Av. & 20.59 & 25.77 & 24.66 & 23.92 \\
\hline B5 & & $S$ & $S$ & 11.43 & 11.57 & 9.62 & 8.36 \\
\hline
\end{tabular}

Note: Negative values are shown within parenthesis; see Fig. 2 for F1-F5.

It may be concluded from the results given therein that for a wide variety of wall widths, as the bed mortar thickness increases, the hourly outputs increase too sometimes by as much as $25 \%$. (Note: The F/S/Av combination is of no significance as the reduction is negligible). Nevertheless, it should be noted that this conclusion is only valid as so long as current methods of constructions are adopted. For example, if two bricks were to be picked up at a time, instead of the current practice of picking up one brick at a time, then the situation may change to an ' $F / S / A v$ '. Similarly, if a larger trowel is used (instead of the $20 \mathrm{~cm} \times 10 \mathrm{~cm}$ trowel to a larger trowel used with concrete-work), then the situation may change to an 'S/F/Av'. However, the usefulness of this simulation methodology is that, in the event of such an eventuality, its impact can be assessed by resorting to a 'sensitivity-analysis' as outlined herein (which a regression model built on historical data cannot do).

The data in Table 5 also show that as walls become broader (with an accompanying increase in the size of the brick) there is a gradual decline in the 'increase' associated with the doubling of the bed joint. This is explainable, as an increase in brick size means an increase in the rate of placing a cubic meter of brick. Furthermore, it can be shown that broad features portrayed by data in Table 4 remain much the same when walls are built with chapparu, and also when taller bricks are used (see [12]).

Thus, the implication to practice is that output can be increased by increasing bed joint thickness. The magnitude of the increase depends on various factors. However, substantial increases $(<25 \%)$ are possible using prevailing methods of construction. Clearly, higher the rates of spreading mortar, higher will be the percentage increase when large bed joints are used. Moreover, the sizes must be buildable [14]. If, however, a different method was used to build walls, what is useful to note is that the procedure described herein could be used to evaluate the impact but not with regression type models.

\section{The Impact of Chapparu 7.1 In General}

As explained in Section 2, chapparu can be categorised into three types based on how it is used in practice viz. only on one side, on both sides, and on alternating sides. Whilst the first two types are more common, the alternating type is uncommon. Incidentally, the latter type is referred to as the 'mata thunai' or as the 'three-for-me' method to mean that when a 
pair of bricklayers work on either side of a wall, each bricklayer encounters chapparu only once in three courses. Of the three methods, the best appears to be the one with the chapparu on both sides as it is not necessary to plumb or align the bricks in the $\mathrm{h} / \mathrm{c}$ with chapparu. Perhaps, the advantages are greater with respect to shorter walls in view of the larger time spent on plumbing and levelling.

\subsection{Impact of Small Values of Chapparu}

In view of the comments made in the above section on the advantage of using chapparu on both sides, a study was made of this feature by comparing outputs of walls without chapparu with walls with the minimum buildable chapparu (i.e. $6 \mathrm{~mm}$ ) with different wall widths and bed joints. The results are given in Table 6.

The results in Table 6 show that the difference in output is negligible especially when working with average rates (see shaded area). The F/S/Av case, however, indicates a marginal decline; of course, the probability of such a scenario in practice would also be low. It may be shown that even when the brick size increases (say to $55 \mathrm{~mm}$ ), the difference is still marginal. Thus, it may be concluded that when walls are built with the smallest size of chapparu the difference is negligible.

This conclusion is an important one, as it partly counters the allegation that chapparu walls take longer to build (as noted in Section 2). Clearly, this is not the case in the large majority of cases (when working at average and faster rates). Thus, chapparu can be used to cope with the chaos in Sri Lankan brickwork. Of course, it should not be forgotten that this conclusion is only valid with the smallest buildable chapparu. Is this the case with large chapparu? This is investigated in the next section.

\subsection{Impact of Large Values of Chapparu}

This aspect is investigated further by comparing simulated outputs of standard width walls with matching brick sizes (avoiding the need for chapparu) and walls with brick sizes yielding different sizes of chapparu ranging from 10 to $40 \mathrm{~mm}$, in steps of $10 \mathrm{~mm}$ (with a bed mortar thickness of $20 \mathrm{~mm}$ ). The hourly outputs were calculated (as before) using the procedure outlined in Section 5. The results so obtained are given in Table 7 . The following broad observations can be made from this Table:

i. The hourly output reduces as the size of the chapparu increases; the impact of the wall width is negligible.

ii. The lowest reduction in output results when activities are carried out at average rates.

iii. The impact of a $10 \mathrm{~mm}$ chapparu is insignificant $(<3.5 \%)$.

iv. The impact of a $20 \mathrm{~mm}$ chapparu is marginal $(<12.63 \%)$ except for the F/S/Av case.

Table 6:

Percent increase in hourly output with small values of chapparu over those without DATA: $\mathrm{TS}=\mathrm{TH}=15 \mathrm{~mm}$; Medium type sand; F1 $=1.1577 ; \mathrm{F} 2-\mathrm{F} 5=1.0$

\begin{tabular}{|c|c|c|c|c|c|c|c|}
\hline \multirow[b]{2}{*}{ Brick size (mm) } & \multirow{2}{*}{$\begin{array}{c}\text { Wall } \\
\text { Width }\end{array}$} & \multirow[b]{2}{*}{$\mathrm{BMT}$} & \multicolumn{5}{|c|}{ Combination } \\
\hline & & & $S / S / S$ & $\overline{\mathrm{Av} / \mathrm{Av} / \overline{\mathrm{Av}}}$ & $\mathrm{F} / \mathrm{F} / \mathrm{F}$ & $\mathrm{S} / \mathrm{F} / \mathrm{Av}$ & $\mathrm{F} / \mathrm{S} / \mathrm{Av}$ \\
\hline \multirow{3}{*}{$\begin{array}{l}190 \times 92.5 \times 45 \\
184 \times 87 \times 45^{\star}\end{array}$} & 190 & 10 & $(0.57)$ & 0.43 & 0.43 & 4.09 & $(5.63)$ \\
\hline & & 20 & $(0.52)$ & 0.39 & 0.40 & 3.93 & $(4.82)$ \\
\hline & & 30 & $(0.48)$ & 0.36 & 0.37 & 3.78 & $(4.21)$ \\
\hline \multirow{3}{*}{$\begin{array}{l}200 \times 97.5 \times 45 \\
194 \times 92 \times 45^{*}\end{array}$} & 200 & 10 & $(0.38)$ & 0.65 & 0.62 & 4.48 & $(5.54)$ \\
\hline & & 20 & $(0.35)$ & 0.58 & 0.57 & 4.29 & $(4.70)$ \\
\hline & & 30 & $(0.31)$ & 0.53 & 0.53 & 4.12 & $(4.08)$ \\
\hline \multirow{3}{*}{$\begin{array}{c}215 \times 105 \times 45 \\
209 \times 99.5 \times 45^{\star}\end{array}$} & 210 & 10 & $(0.13)$ & 0.93 & 0.88 & 5.03 & $(5.41)$ \\
\hline & & 20 & $(0.12)$ & 0.83 & 0.80 & 4.80 & $(4.54)$ \\
\hline & & 30 & $(0.10)$ & 0.75 & 0.73 & 4.58 & (3.91) \\
\hline \multirow{3}{*}{$\begin{array}{c}225 \times 110 \times 45 \\
219 \times 104.5 \times 45^{*}\end{array}$} & 225 & 10 & 0.016 & 1.09 & 1.03 & 5.37 & $(5.33)$ \\
\hline & & 20 & 0.014 & 0.97 & 0.93 & 5.10 & $(4.44)$ \\
\hline & & 30 & 0.013 & 0.87 & 0.85 & 4.86 & $(3.80)$ \\
\hline
\end{tabular}

Negative values are given within parenthesis; Minimum buildable size of chapparu taken as $5 \mathrm{~mm}$.

* Refer to walls with chapparu (e.g. 190-184=6). All dimensions are millimetres. See Fig. 2 for F1-F5

interpretations. F/F/F notations as before in the order of bricks, mortar, and relaxation (see Table 4) 
Table 7:

Percentage increase of hourly outputs of walls with large values of chapparu over those without

\begin{tabular}{|c|c|c|c|c|c|c|c|c|}
\hline \multicolumn{9}{|c|}{$\begin{array}{l}\text { DATA: } \\
\text { Length of wall: } 3.5 \mathrm{~m} \text {; Medium type sand; TS } \\
\text { Bed mortar thickness (BMT) }=20 \mathrm{~mm} \text {. }\end{array}$} \\
\hline \multicolumn{9}{|c|}{ Brick sizes for walls without chapparu (mm): } \\
\hline & \multirow{2}{*}{\multicolumn{3}{|c|}{$\begin{array}{l}\text { Case 1: TW }=190 ; 190 \times 92.5 \times 45 \\
\text { Case 2: } T W=200 ; 200 \times 97.5 \times 45\end{array}$}} & \multirow{2}{*}{\multicolumn{5}{|c|}{$\begin{array}{l}\text { Case } 3: T W=215 ; 215 \times 105 \times 45 \\
\text { Case 4: TW }=225 ; 225 \times 110 \times 45\end{array}$}} \\
\hline & & & & & & & & \\
\hline & $\begin{array}{l}\text { Brick size for walls } \\
\text { with chapparu }\end{array}$ & $\begin{array}{l}\text { WT } \\
(\mathrm{mm})\end{array}$ & $\begin{array}{l}\text { Chapparu } \\
\text { (mm) }\end{array}$ & Slowest & Av. & Fastest & $\mathrm{S} / \mathrm{F} / \mathrm{Av}$ & F/S/Av \\
\hline \multirow[t]{4}{*}{1} & $180 \times 87.5 \times 45$ & \multirow[t]{4}{*}{190} & \multirow{4}{*}{$\begin{array}{l}10 \\
20 \\
30 \\
4.0\end{array}$} & $(3.50)$ & $(2.06)$ & (3.09) & 2.39 & $(10.50)$ \\
\hline & $170 \times 82.5 \times 45$ & & & $(12.51)$ & $(10.09)$ & $(12.84)$ & $(5.36)$ & $(21.79)$ \\
\hline & $160 \times 77.5 \times 45$ & & & $(20.17)$ & $(17.11)$ & $(20.99)$ & $(12.30)$ & $(30.65)$ \\
\hline & $150 \times 72.5 \times 45$ & & & $(26.78)$ & $(23.32)$ & (27.92) & $(18.58)$ & $(37.79)$ \\
\hline \multirow[t]{4}{*}{2} & $190 \times 92.5 \times 45$ & \multirow[t]{4}{*}{200} & \multirow{4}{*}{$\begin{array}{l}10 \\
20 \\
30 \\
4.0\end{array}$} & (3.34) & $(1.88)$ & (2.93) & 2.17 & $\overline{(8.74)}$ \\
\hline & $180 \times 87.5 \times 45$ & & & $(12.27)$ & $(9.81)$ & (12.63) & $(5.25)$ & $(19.27)$ \\
\hline & $170 \times 82.5 \times 45$ & & & (19.85) & $(16.74)$ & $(20.72)$ & $(11.94)$ & $(27.71)$ \\
\hline & $160 \times 77.5 \times 45$ & & & $(26.40)$ & (22.87) & $(27.59)$ & $(18.00)$ & $(34.64)$ \\
\hline \multirow[t]{4}{*}{3} & $205 \times 100 \times 45$ & \multirow[t]{4}{*}{215} & \multirow{4}{*}{$\begin{array}{l}10 \\
20 \\
30 \\
40\end{array}$} & (3.12) & (1.64) & (2.73) & 2.63 & $(8.53)$ \\
\hline & $195 \times 95 \times 45$ & & & $(11.94)$ & $(9.45)$ & (12.34) & $(4.69)$ & (18.89) \\
\hline & $185 \times 90 \times 45$ & & & $(19.43)$ & $(16.26)$ & (20.35) & $(11.27)$ & $(27.21)$ \\
\hline & $175 \times 85 \times 45$ & & & (25.88) & $(22.26)$ & $(27.15)$ & $(17.22)$ & $(34.05)$ \\
\hline & $215 \times 105 \times 45$ & \multirow[t]{4}{*}{225} & \multirow{4}{*}{$\begin{array}{l}10 \\
20 \\
30 \\
40\end{array}$} & (2.99) & $(1.50)$ & $(2.61)$ & 2.91 & $(8.39)$ \\
\hline & $205 \times 100 \times 45$ & & & $(11.75)$ & $(9.23)$ & $(12.16)$ & $(4.36)$ & $(18.64)$ \\
\hline & $195 \times 95 \times 45$ & & & $(19.17)$ & $(15.96)$ & $(20.13)$ & $(10.88)$ & $(26.89)$ \\
\hline & $185 \times 90 \times 45$ & & & $(25.57)$ & $(21.91)$ & (26.89) & $(16.76)$ & $(33.68)$ \\
\hline
\end{tabular}

Negative values are given within parenthesis; Minimum buildable size of chapparu $=6 \mathrm{~mm}$

The impact of taller brick sizes and underfilled joints were also studied [13]. The use of taller bricks increases the impact of chapparu only marginally, whilst the impact of underfilled cross joints (i.e. at $3 / 4$ full) is insignificant. Therefore, it may be concluded that, if chapparu is used in moderation $(<10 \mathrm{~mm})$, its impact on hourly output could be minimised although it must be noted that the notion that chapparu walls take too long to build could be refuted at small values of chapparu. The following sections throw further light on this issue.

\section{The Impact of Vertical Joints}

\subsection{The Size of Joints}

Conventional brickwork requires that bricks in alternate courses be laid with a lap to avoid joints in the same vertical plane. For example, when bricks are laid in English bond or in stretcher bond, cross joints do not fall in the same vertical plane. Consequently, these walls are considered to be strong. In contrast, if the Flemish bond is used, the bond pattern is such that some joints in overlapping courses fall in the same vertical plane. Accordingly, walls with such bonds are considered to be less strong. Such considerations on strength are of less importance for walls that carry light loads or self standing (as in partition walls).

To illustrate the impact of avoiding joints in the same plane, consider a dimensionally uncoordinated brick size of $169 \times 85 \times 43 \mathrm{~mm}$, similar in size to the brick manufacturer's friendly format of $L \approx 2 B$. In order to avoid joints in the same plane, with a quarter lap arrangement (as shown in Fig. 3), TS $+\mathrm{L}$ should be equal to $2 \mathrm{~B}+2 \mathrm{TH}$. This means that TS and TH are in fact inter-related, in the event lap is to be maintained. 


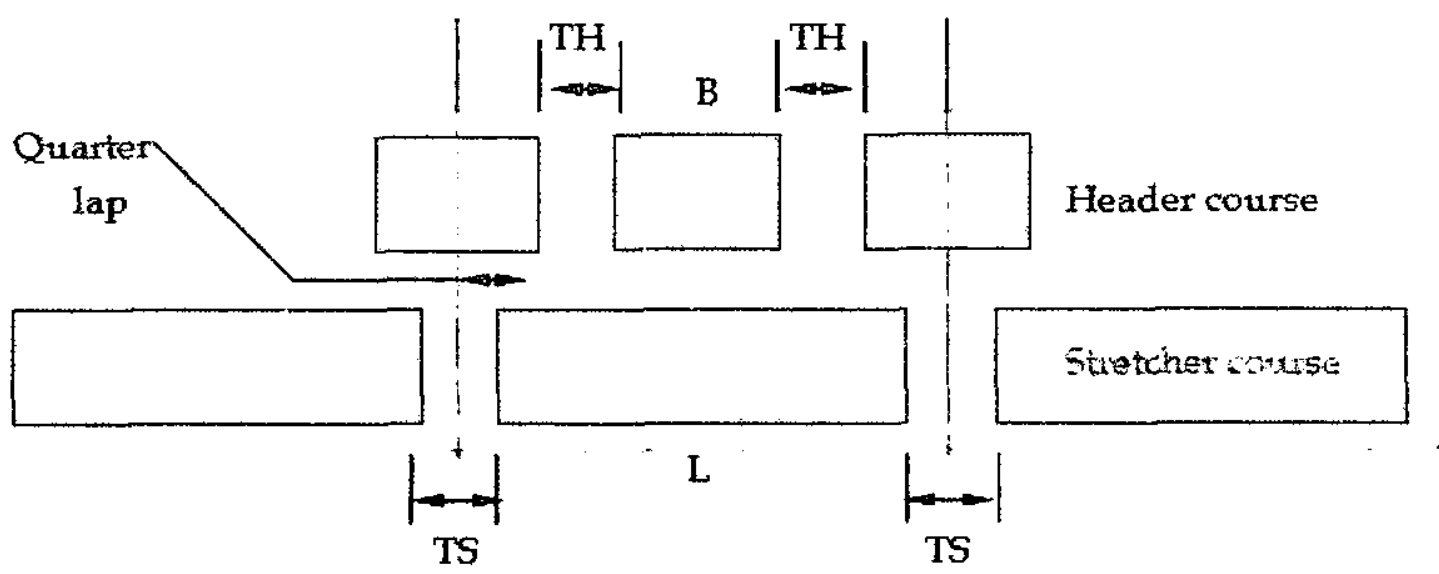

Fig. 3:

Arrangement for maintaining non-verticality of joints with quarter lap

Substituting the dimensions of the chosen brick, the relationships mentioned earlier reduces to -

$$
\mathrm{TS}=1 \mathrm{~mm}+2 \times \mathrm{TH}
$$

If, $\mathrm{TH}$ is $10 \mathrm{~mm}$ (i.e. say a finger-size) then TS must be at least $21 \mathrm{~mm}$. It must be said that the length of the wall to be built would also have a similar effect when fixing such sizes. Situations of this nature may be avoided if preference is not given to the practice of maintaining a quarter-lap as shown above unless of course large joint sizes are preferred in order to reduce costs [15], [16]. In fact, if an extreme view is taken, bricks can even be laid without a cross joint as there is no significant impact on strength as noted before [10], particularly if there are benefits, such as the opportunity to reduce costs as when cost-density of mortar is significantly greater than that of bricks. Clearly, there is much potential for improvisation with chapparu brickwork given the construction culture that prevail in Sri Lanka [17]. Thus, it would be useful to adopt a 'flexible' approach to lap length and joint sizes. The results of a simulated output where the stretcher and header course joints are reduced from 20 to $10 \mathrm{~mm}$ are given in Table 8 throw light on the extent of the impact cross joints have on output.

Data in Table 8 therefore confirm the initial assertion made in Section 4.1 that as the sizes of cross joints are reduced, the hourly outputs increase. In fact, it can be shown by a similar simulation that hourly outputs for 190, 200, 215 and $225 \mathrm{~mm}$ walls could be increased by $31 \%$, $33 \%, 37 \%$ and $38 \%$ respectively, at average activity rates, by reducing the size of the joints from $20 \mathrm{~mm}$ to zero!

Thus, the implication to practice is that a reduction in sizes of cross joints has the potential to increase hourly outputs, and viceversa. As such, considerable savings are possible (often $>10 \%$ ) as evidenced from the above discussion. Nevertheless, the extent of these savings depending on the rates of carrying out various macro activities that is within the control of the worker and the management.

\subsection{Under-filled Vertical Joints}

The issue of either using or avoiding underfilled cross joints can be argued on similar lines to those given in 8.1. Results of a simulated output with a joint fullness factor of $75 \%$ (excluding the bed joint), provide results similar to the above section [18].

Thus, implications to practice are that underfilled joints results in a double 'advantage', with higher hourly outputs and lower mortar volumes. Such a situation may be achieved in practice by moving away from the conventional practice of 'shoving' mortar into joints to simply spreading mortar along the course allowing mortar to fall into joints. However, it is noted that this practice may not be acceptable to all in industry. Nevertheless, given that there is good evidence to suggest that the impact of unfilled joints on strength is insignificant [10]; the use of such joints may be entertained. 
Table 8:

Increase in output (\%) when reducing stretcher/header course joints from $20 \mathrm{~mm}$ to $10 \mathrm{~mm}$

\begin{tabular}{|c|c|c|c|c|c|c|c|}
\hline Brick size (mm) & Wall & \multirow{2}{*}{$\begin{array}{c}\text { BMT } \\
\text { Chapparu =6 mm }\end{array}$} & \multicolumn{5}{|c|}{ Combination } \\
\cline { 5 - 8 } & width $(\mathrm{mm})$ & $(\mathrm{mm})$ & S/S/S & Av/Av/Av & F/F/F & S/F/Av & F/S/Av \\
\hline $184 \times 87 \times 45$ & 190 & 10 & 12.03 & 12.68 & 15.47 & 3.23 & 25.99 \\
\hline $194 \times 92 \times 45$ & 200 & 10 & 12.84 & 13.52 & 16.33 & 3.96 & 26.57 \\
\hline $209 \times 99.5 \times 45$ & 210 & 10 & 13.92 & 14.65 & 17.48 & 4.96 & 27.27 \\
\hline $219 \times 104.5 \times 45$ & 225 & 10 & 14.57 & 15.33 & 18.17 & 5.57 & 27.66 \\
\hline
\end{tabular}

\section{The Impact of Brick Size}

The focus herein is to examine the impact of the variation in brick size on a particular wall width. Accordingly, two aspects were studied; The first study, evaluates the changes in output by changing the brick size at constant height with respect to the four 'prescribed' widths of walls noted earlier(i.e. 190, 200, 215, and $225 \mathrm{~mm}$ ) and with three different sizes of bed joints (i.e. 10, 20 and $30 \mathrm{~mm}$ ). In effect, this amounts to varying the size of chapparu (but not with a fixed brick size as analysed in 8.10.2). The main conclusion which can be drawn from this investigation is that if brick sizes are selected so that chapparu is kept to less than about $12 \mathrm{~mm}$ (i.e. $1 / 2^{\prime \prime}$ ), then the impact in the reduction in output is marginal (Abeysekera, 1997, Appendix 8.6).

In the second study, the length and the breadth of the brick is kept constant and the height is varied from $45 \mathrm{~mm}$ to $55 \mathrm{~mm}$, with respect to two scenarios, i.e. walls with the mininum buildable chapparu of $6 \mathrm{~mm}$, and walls double this amount (i.e. $12 \mathrm{~mm}$ ). The main conclusion that can be drawn from this investigation is that, as the height of the brick increases, there is an increase in the output as well. At average rates, an increase of $10 \mathrm{~mm}$ (above a $45 \mathrm{~mm}$ brick height) results in an increase around $8 \%$ (irrespective of the width of the wall), whilst an increase of $20 \mathrm{~mm}$ results in an increase of around $16 \%$ with a chapparu of $6 \mathrm{~mm}$. The difference in output when the chapparu is increased to $12 \mathrm{~mm}$ is insignificant (when compared with $8 \%$ noted above) with the increase dropping to around $7 \%$ [19].

\section{A General Specification for Output Decisions}

Discussions thus far centred on the impact of brick and joint sizes on output of chapparu brickwork. Assertions made in Section 4 were analysed and concluded. Accordingly, the following broad recommendations are made as a basis for optimising brickwork output.

The extent of the improvements possible depends on the judicious use of brick and joint sizes as exemplified throughout this paper. In order to further illustrate the impact of the general specification above, a few cases have been considered with results given in Table 9.

- Minimise chapparu to $<10-12 \mathrm{~mm}$ by selecting a suitable brick.

- Maximise size of bed joint (to a 'convenient/controlled/buildable' size).

- Use smaller vertical joints; adopt a flexible approach to lap requirements and joint sizes.

- Use under filled/unfilled cross joints.

- Select taller (i.e. larger) bricks.

Note: These recommendations may not necessarily reduce costs [17], [18]

Fig. 4: A General Specification for optimising hourly output 
Table 9:

Output indicators with average rates of macro-activities

\begin{tabular}{|c|c|c|c|c|c|c|c|c|}
\hline $\mathrm{Me}$ & ium & ind F1 (bed joi & $=1$ & & Coml & tation & r macro-ac & ity rates $-\mathrm{Av} / \mathrm{Av} / \mathrm{Av}$ \\
\hline \multirow{6}{*}{$\begin{array}{c}\text { Wall } 1 \\
\text { Chapparu } \\
6 \mathrm{~mm}\end{array}$} & TW & Brick size & $\begin{array}{l}\text { F2- } \\
\text { F5 }\end{array}$ & $\mathrm{TH}$ & TS & BMT & $\begin{array}{l}\text { Output } \\
\text { Indicator }\end{array}$ & Remarks \\
\hline & 190 & $184 \times 89.5 \times 45$ & 1 & 10 & 10 & 10 & 100 & \\
\hline & & & & & & 20 & 108 & $\begin{array}{c}\text { Only a } 8 \% \text { increase doubling bed } \\
\text { joint }\end{array}$ \\
\hline & & & & & & 30 & 114 & A $14 \%$ with trebling bed joint \\
\hline & & & & 0 & 0 & 20 & 122 & $\begin{array}{l}\text { A } 22 \% \text { increase doubling the bed } \\
\text { joint but zero vertical joints }\end{array}$ \\
\hline & & & & 0 & 0 & 30 & 127 & \\
\hline \multirow{4}{*}{$\begin{array}{c}\text { Wall } 2 \\
\text { Chapparu } \\
10 \mathrm{~mm}\end{array}$} & 215 & $205 \times 100 \times 45$ & 1 & 10 & 10 & 10 & 100 & \\
\hline & & & & & & 20 & 106 & $\begin{array}{c}\text { Only a } 6 \% \text { increase doubling the } \\
\text { bed joint }\end{array}$ \\
\hline & & & & 0 & $\overline{0}$ & 20 & 123 & $\begin{array}{l}\text { A 23\% increase doubling bed joint } \\
\text { and zero vertical joints }\end{array}$ \\
\hline & & & & 0 & 0 & 30 & 127 & \\
\hline \multirow{3}{*}{$\begin{array}{c}\text { Wall } 2 \\
\text { Chapparu } \\
10\end{array}$} & 215 & $205 \times 100 \times 55$ & 1 & 10 & 10 & 10 & 103 & $\begin{array}{c}\text { Only a } 3 \% \text { increase with a taller } \\
\text { brick }\end{array}$ \\
\hline & & & & & & 30 & 112 & \\
\hline & & & & 0 & 0 & 20 & 129 & $\begin{array}{l}\text { A } 25 \% \text { increase with zero vertical } \\
\text { joints but double the bed joint }\end{array}$ \\
\hline
\end{tabular}

It should be pointed out that increases in output may not necessarily translate into cost savings. For example, if higher outputs are achieved through larger bed joints, the costs may increase if cost density of mortar is significantly higher than the cost density of bricks. Moreover, if work is subcontracted, savings through the achievement of higher outputs may not materialise unless the subcontractors give better rates. Additionally, joint sizes should be buildable [15]. Likewise, a decision to under-fill vertical joints may not necessarily translate into cost savings if the cost density of brick is significantly higher than that of mortar. For these and other discussions, readers are advised to refer to a publication by the author on 'Optimising Brickwork Costs in a Chaotic and Complex Environment' [15] and 'Cost Related Strategies for Managing Large Scale Operations in a Chaotic Environment' [16].

\section{Conclusions}

The main aim of this study was to understand the impact of brick and joint sizes on output of chapparu walls. The general specification given in Section 10 provides information how brickwork could be optimised whilst noting that when chapparu is used in moderation $(<10-12 \mathrm{~mm})$, the impact on output is negligible. The opportunity to increase output by increasing the bed joint size over and above those used in walls built with dimensionally coordinated bricks is a useful discovery as it presents the opportunity to reduce costs particularly in an environment where the cost density of mortar is less than that of bricks. Moreover, there are significant opportunities to increase output through under-filled joints and/or smaller (or zero) vertical joints as well particularly in lightly loaded walls. If the latter is to be considered, it would be necessary to avoid complying rigidly with 'lap' lengths, in which case, it will be necessary to allow joint sizes to vary from brick to brick and course to course without exercising control on an exact size thereby doing away with the interdependency of vertical joint sizes. However, an increase in output may not necessarily result in cost savings as explained throughout. this paper. Thus, decisions on whether to increase output or not through such strategies need to considered thoughtfully and taken judiciously. Interestingly, if a computer programme were to be developed with regard to output optimisation capability, such decisions could be made easily.

The simulation methodology developed in this paper as many different scenarios can be evaluated with relative ease. Moreover, with the understanding so gained, different types of 
chapparu walls can be studied including the 'mata-thunai' type of chapparu wall. Future studies could also focus on half brick thick walls and the development of a computer programme to facilitate decision making.

It is expected that this study clear some common understandings surrounding chapparu brickwork that has spanned well over a century making it possible to rationalise practices connected with brickwork and exploring new opportunities through the nonstandardisation route!

\section{References}

1. Abeysekera, V., \& Thorpe, A., A New Technology to bring 'Order' out of 'Chaos'? The Case of Brickwork in Sri Lanka and Bangladesh, International Conference on Construction Industry Development, eds., National University of Singapore in association with CIDB (Singapore), ACl (US), ACI (Australia), ACI (UK), Singapore, December, 179-189, 1997.

2. Abeysekera, V., \& Thorpe, A., Standardisation or Non-Standardisation: The Case of Sri Lankan Brickwork. 13th ARCOM Conference, U.K., September, 177-86, 1997.

3. Dissanayake, D.D.A., Muthunayake, M.S., \& Shiraz, M.F., Productivity Study on Brickwork, undergraduate project report, Department of Civil Engineering, University of Moratuwa, Sri Lanka, 1993.

4. Kellapatha, N.P. Comparative Analysis of Traditional Brickwork and Concrete Blockwork, undergraduate project report, Dept. of Building Economics, University of Moratuwa, Sri Lanka, 1993.

5. Jayawardane, A.K.W., Price, A.D.F., \& Harris, F.C., Measurement of Brickwork and Blockwork productivity: Parts A and B, Building Research and Information, Vol. 23, No. 2, 1995.

6. Abeysekera, W.V.K.M, A Strategy for Managing Brickwork in Sri Lanka, PhD Thesis, Loughborough University, U.K., Appendices 8.12-19, 1997 (unpublished).

7. Harris, F., \& McCaffer, R., Modern Construction Management, $5^{\text {th }}$ ed., Blackwell Science, 2001

8. Currie, R.M., Work Study, revised by Faraday, J.E., $4^{\text {th }}$ ed., Pitman Publishing, 1977.

9. Abeysekera, W.V.K.M., A Strategy for Managing Brickwork in Sri Lanka, PhD Thesis, Loughborough University, U.K., Chapters 5:Theoretical Framework for Mortar
Consumption Studies \& Chapter 6: Mortar Consumption Characteristics, 1997.

10. Hendry, A.W., Workmanship Factors in Brickwork Strength, BDA Technical Note, Vol 1, No. 6, Nov. 1972.

11. Abeysekera, W.V.K.M. A Strategy for Managing Brickwork in Sri Lanka, PhD Thesis, Loughborough University, U.K., Chapter 3: A Profile of the Chaos in Sri Lankan Brickwork, p. 73, 1997 (unpublished).

12. Abeysekera, W.V;K.M., A Strategy for Managing Brickwork in Sri Lanka, PhD Thesis, Loughborough University,. U.K., Appendices 8.4-8.5, 1997 (unpublished).

13. Abeysekera, W.V.K.M., A Strategy for Managing Brickwork in Sri Lanka, PhD Thesis, Loughborough University, U.K., Appendices $8.9,8.10 \& 8.11,1997$ (unpublished).

14. Abeysekera, V., \& Thorpe, A., Bricklayers' perspectives on the buildability of the bed-joint and the threat to standardisation vis-a-vis cost optimisation, Challenges and opportunities in management and technology, 1st International Conference on Construction in the 21st Century, eds. I. Ahmad, S. Ahmed, and S. Azhar, Florida International University, Miami, U.S.A., 25-25 April, 33-40, 2002.

15. Abeysekera, V., \& Thorpe, A., Optimising Brickwork Costs in a Complex and Chaotic Environment, Journal of the Institution of Engineers, Volume 1 - Part B, Transactions, 94110, 1997.

16. Abeysekera, V., \& Thorpe, A. (2001), Cost Related Strategies for Managing Large Scale Operations in a Chaotic Environment. International Conference on Project Cost Management, A. Liu, R. Fellows, and D. Drew, eds., The Department of Standard and Norms, Ministry of Construction, People's Republic of China, Beijing, China, 25-27 May, 125-136, 2001.

17. Abeysekera, V., Understanding 'culture' in an international construction context, eds. F. Fellows \& D. Seymour, Perspectives on culture in construction, Rotterdam, The Netherlands, International Council for Research and Innovation in Building and Construction (CIB), pp. 39-51, 2002.

18. Abeysekera, W.V.K.M., A Strategy for Managing Brickwork in Sri Lanka, PhD Thesis, Loughborough University, U.K., Appendix 8.8, 1997.

19. Abeysekera, W.V.K.M., A Strategy for Managing Brickwork in Sri Lanka, PhD Thesis, Loughborough University, U.K., Appendix 8.7, 1997 (unpublished). 
20. Wijetunga, H., Practical Sinhala Dictionary, Vol. 1, Ministry of Cultural Affairs, Sri Lanka, 1982.

21. Abeysekera, W.V.K.M., A Strategy for Managing Brickwork in Sri Lanka, PhD Thesis, Loughborough University, U.K., Chapter 5, p. 136, 1997 (unpublished).
22. Chandrakeerthi, S.R. de S., Local Bricklaying Practices, Transactions, Institution of Engineers Sri Lanka, p. 90-102, 1987

\section{Appendix 1: List of Micro/Macro-Activities used for Activity Sampling Studies}

(A) Activity Sampling Categories

\begin{tabular}{|c|c|c|c|}
\hline \multicolumn{2}{|c|}{ Category } & & \multirow[t]{2}{*}{ Description } \\
\hline Main & Sub & & \\
\hline 1 & & - & Fetch bricks \\
\hline & $t$ & - & Travel to fetch bricks \\
\hline & $s$ & - & Sorting bricks for size \\
\hline 2 & & - & Break bricks \\
\hline 3 & & - & Place bricks \\
\hline 4 & & - & Set line \\
\hline 5 & & - & $\begin{array}{l}\text { Fetch mortar (Note: It was difficult to separate this activity to } \\
\text { with respect to different joints) }\end{array}$ \\
\hline & $\mathbf{t}$ & - & Travel to fetch mortar \\
\hline 6 & & - & Mix mortar \\
\hline 7 & & - & Collect/pick mortar \\
\hline 8 & & - & Spread bed mortar (including mortar falling into wall joint) \\
\hline 9 & & - & $\begin{array}{l}\text { Fill/shovel mortar into cross joints (any spreading of mortar } \\
\text { for this purpose included under this category) }\end{array}$ \\
\hline 10 & & - & Chapparu \\
\hline 11 & & - & Rake joints \\
\hline 12 & $\mathrm{pb}$ & - & Check for verticality with plumb bob \\
\hline & se & - & Check for verticality with straight edge \\
\hline 13 & & - & Set up work \\
\hline 14 & $\mathrm{~m}$ & - & Waiting beyond the control of mason due to lack of materials \\
\hline & 1 & - & Waiting beyond the control of mason due to lack of labour \\
\hline & $\mathrm{ms}$ & - & Waiting for other mason to complete his part of the work \\
\hline 15 & & - & Idling/relaxing \\
\hline 16 & & - & Recover \\
\hline 17 & & - & Giving/receiving instructions \\
\hline 18 & & - & Away from work locality \\
\hline 19 & & - & Other work (inspecting) \\
\hline 20 & $\begin{array}{l}\mathrm{c}, \mathrm{s}, \mathrm{b}, \\
\mathrm{m}, \mathrm{w}\end{array}$ & - & Load (cement, sand, bricks, mortar, water) \\
\hline 21 & $\begin{array}{l}\mathrm{c}, \mathrm{s}, \mathrm{b}, \\
\mathrm{m}, \mathrm{w}\end{array}$ & - & Unload (cement, sand, bricks, mortar, water) \\
\hline 22 & $\begin{array}{l}c, s, b \\
m, w\end{array}$ & - & Transport (cement, sand, bricks, mortar, water) \\
\hline 24 & & - & Measure \\
\hline 25 & & - & Stacking bricks after transportation \\
\hline
\end{tabular}


(B) List of macro-activities and link with micro-activities

Item in Table: $\quad$ Classification Item

1. Set line: 4

2. Plumb brick: $\quad 12$

3. Fetch brick: 1, 1s

4. Place brick: 3

5. Travel to fetch brick: 1t

6. Fetch mortar: 5

7. Spread bed mortar: 8

8. Fill perpend joints: 9

9. Chapparu: 10

10. Other: 2,6,7,11,13,20-25

11. Idle/Recover/Relax: 14-18

\section{Appendix 3: Details of field walls}

\begin{tabular}{|l|c|c|c|c|c|}
\hline Case & 1 & 2 & 3 & 4 & 5 \\
\hline Unit Averages of bricks: (cm) & & & & & \\
\hline Length & 19.46 & 18.65 & 20.07 & 19.74 & 19.26 \\
\hline Breadth & 10.17 & 9.07 & 9.48 & 9.58 & 9.30 \\
\hline Height & 5.23 & 4.39 & 5.13 & 5.31 & 5.10 \\
\hline Wall thickness(cm) & 20.8 & 20.0 & 20.9 & 20.5 & 19.26 \\
\hline Wall length (m) & 3.695 & 8.873 & 2.472 & 2.38 & 5.033 \\
\hline Wall height (m) & 0.645 & 0.875 & 2.472 & 2.38 & 0.860 \\
\hline No. of courses & 9 & 13 & 13 & 19 & 13 \\
\hline Joint sizes: (mm) & & & & & \\
\hline Bed mortar joint & 21.07 & 23.41 & 13.67 & 10.00 & 15.15 \\
\hline Chapparu joint & 14.40 & 13.50 & 8.30 & 20.50 & 0.00 \\
\hline S/c cross joint & 25.04 & 19.85 & 24.85 & 12.16 & 22.50 \\
\hline S/c wall joint & 9.40 & 18.60 & 19.40 & 18.96 & 5.60 \\
\hline H/c cross joint & 2.61 & 9.998 & 12.78 & 13.40 & 16.66 \\
\hline Joint fullness factors (see Fig. 2 for details) & & & & & \\
\hline F1 - bed joint & 1.3889 & 1.15 & 1.3889 & 1.3889 & 1.13889 \\
\hline F2 - chapparu & 1.00 & 1.00 & 1.00 & 1.00 & - \\
\hline F3 - header course cross joint & 0.75 & 0.50 & 0.75 & 0.75 & 0.75 \\
\hline F4 - stretcher course cross joint & 1.00 & 1.00 & 1.00 & 1.00 & 0.75 \\
\hline F5 - wall joint & 0.75 & 1.00 & 0.75 & 0.50 & 0.15 \\
\hline Study duration (hrs.) & & & & & \\
\hline
\end{tabular}

